\title{
A Review: Language Awareness from the Perspective of Vocabulary Variation and Change
}

\author{
Wei Zhou*, Peihong Xu, Quan Zhao \\ Anhui Vocational and Technical College, Hefei 230011, China \\ *Corresponding author: Wei Zhou, zwizd@126.com
}

\begin{abstract}
Language awareness refers to the consciousness of what language is and how language works. The process of establishing or developing language awareness should be a discovery of language use by learners themselves, maybe under the guidance of teachers. In this way, language awareness is considered not only as a linguistic term, but also a pedagogical approach. Just like society, change is also constant in the world of language. This paper aims to provide a reflection on language awareness from the angle of vocabulary variations and changes.
\end{abstract}

Keywords: Language awareness; Vocabulary variations; Changes; Time; Users; Social culture; Reflection

Publication date: December 2021; Online publication: December 27, 2021

\section{Introduction}

This article is divided into three sections: language awareness and the factors that influence language usage, vocabulary variety and change as well as personal reflection. The notion of language awareness will be presented first in part one, followed by a quick overview of language in use and the elements that influence it, such as time, users, and social culture. In section one, we explore linguistic diversity and change in a broad sense. The second part consists of a thorough explanation from the standpoint of vocabulary. The final section focuses on personal reflection and application from the perspective of a language teacher.

\section{Language awareness and variables affecting language use}

\subsection{The concept of language awareness}

According to Tomlinson et al ${ }^{[1]}$, "language awareness is mental attribute which develops through paying motivated attention to language use, and which enables language learners to gradually gain insights into how language work. It is also a pedagogical approach that aims to help learners to gain insight." Other researchers, also have defined the term of Language Awareness. Even their definitions are clarified differently; it is not difficult to identify several key words recurring in those definitions ${ }^{[2-3]}$. For example, the expressions "features of language," "sensitivity," "consciousness," "how language work," "forms" and "functions."

The key principle of a Language Awareness approach is that students should discover language themselves. Learners are encouraged to collect their own data from daily life instead of asking their teachers. In this way, teachers can help students to develop their insight into how the target language functions ${ }^{[4]}$. Moreover, students can internalize language awareness, which is dynamic and related to intuition, in a gradual way ${ }^{[5]}$. Bolitho and Tomlinson ${ }^{[6]}$ pointed out that language awareness tend to enhance the spirit of exploration of students. However, Van Lier ${ }^{[7]}$ argued that Language Awareness approach include explicit teaching. Regarding this, Tomlinson et al ${ }^{[1]}$ challenged that Language Awareness approach is different from an approach that emphasizes transmitting explicit knowledge to learners. Oppositely, it is an approach focusing on students' gradual internalization and realization of language in use. It is learners' curiosity that 
drives them to explore and produce language in use. Besides, Critical Language Awareness (C.L.A.) is the same approach but emphasizing "the relationship between language and social context ${ }^{[1]}$."

\subsection{Variables affecting language in use}

Language is dynamic and flexible. It can both reflect and be reflected by the changing social life around us. Likewise, it can also influence and be influenced by the interaction within individuals ${ }^{[2]}$. The kind of language to use is decided by users' choices of language structures. Moreover, the linguistic choices can be various due to the flexibility of language. When choosing language to use, context should be taken into consideration. Actually, the context is the key to decode the meanings behind people's linguistic choices. Besides context, the medium to manifest language should also be considered. The medium in language use is likely to reflect the users' attitudes. Talking about attitudes, it not only involves with users' attitudes conveyed in their message, but also their attitudes towards that language. Overall, effectiveness, whether language users have achieved their communicative purpose, is also dictated by their knowledge of the world. As seen from above, language in use, which distinguishes itself from the linguistic systems, involves eight basic features: knowledge of the world, context, variety, medium, attitude, effectiveness, structure and flexibility. These features are all important and easily to overlap with each other ${ }^{[2]}$. The ability to change and adapt brings about the dynamism and flexibility of language. Generally, there are a large number of factors contributing to the language variation and change. For example, time, context, users, geography, imperfect learning, social-culture, the nature of language and so on ${ }^{[8]}$. In this essay, three main factors will be focused on: time, users and social-culture. However, as complex as the features of language in use itself, the variables or factors affecting language use also overlapped to some degree.

\section{Vocabulary variations and change}

\subsection{Time}

Vocabulary variation and change is fascinating and may be also the most obvious area among all the areas of linguistic variation and changes ${ }^{[8]}$. In this section, the vocabulary use of English language will be explored from a chorological perspective; initially I want to talk about the new words and old. When it comes to new words, one of the resources is from historical events, such as wars and invasions, which I will explain in social culture section in detail. In this section, the new words to be discussed are those stems from the language system itself. For instance, in English language, it has affixation, conversion, compounds, backformations, blends, clippings and reduplicative. Among these various processes, the first three terms will be explained here. Affixation refers to the form that provides us prefixes and suffixes. Such as, triangle, transformation, telephone. Conversion means that in English, the same word can function in different grammatical categories. For example, the word bear can serve as a noun, but also a verb. Other examples for conversion include bank, record, and paper. Compounds are a word that includes more than one stem. For instance, wallpaper, bookshop, scarecrow ${ }^{[2]}$. As for the old words, some of them disappear in the English language use. Specifically, when the concept behind a word is no longer valued in the community of target language, the word itself may turn obsolete gradually. It is also possible that the old word has developed negative associations or replaced by a fashionable new word ${ }^{[8]}$. Such as Wight (person), Leman (sweetheart), and conceit (idea).

Regarding the evolution of meanings, the process of broadening and narrowing are very interesting. The word dog is used for all kinds of dogs now, but in old days, docga (its previous form) refers to only one particular breed of dogs. Another amazing example is that the word holiday that generally means a rest time from study or work. However, holy day (its previous form) is religion related. When it comes to the process of narrowing, for instance, mete (the previous form of meat) was used to refer to all kinds of food, while now meat is only for one particular kind of food. Another example is wife, wife can be used for any 
women in the Old English, while it was narrowed down to ladies who have married ${ }^{[9]}$.

There is another interesting example indicating the language variation over time. In American English, there is word druggist, which is a counterpart of chemist in British English. The colonists brought the word druggist from Britain to America. Then in the $18^{\text {th }}$ century, the British people used chemist instead of druggist, while the colonists were not aware of the changes of English language use in their homeland. Thus, keeping using the word druggist in America. The word fall is another example for this situation. Unable to keep up with the language use of their homeland country, colonists used fall instead of autumn.

The final point I want to mention here are coinages, which are not common words, but they are entirely new words ${ }^{[10]}$. Take the word Aspirin as an example, initially, Aspirin is the brand name of a pain-reducing commodity. Over the time, the concept of Aspirin became more and more general. Currently, Aspirin means a medicine which can helps to cure physical pain, but also a metaphor to cure all kinds of pains, even emotional ones.

\subsection{Users}

According to Andrews [10], "Dialects are characterized by variations observed in three basic linguistic features like "lexical or vocabulary variations;" "phonological or accent variations;" "grammatical variations." From the statement above, it is not difficult to figure out that users of different dialects tend to have various choices of vocabulary use. For example, the terms of a frying pan, a fry pan, and a skillet are from three dialects of America. These three difference choices of vocabulary indeed carry the similar meaning: "a heavy pan used for frying chicken". In addition, American English also differs from British English in terms of vocabulary use. For instance, "the dot at the end of the sentence" is called "full stop" in British vocabulary, while "period" in American vocabulary ${ }^{[10]}$. Other examples are such as "drugstore" and "chemist," "fall" and "autumn," which were discussed in the preceding section in this essay.

Variation related to the gender of language user has been the focus of discussion recently. According to the research, women are likely to use more prestigious vocabulary than men. For example, men tend to use forms such as "I taken it" "It growed." While women use expressions like "I took it" "It grew" more frequently. Moreover, the research indicated that female speakers tend to use vocabulary carrying more tentativeness, that is to say, more "hedges" and "tags" are used in their speech, for instance, "Well, em, I think math is sort of boring, don't you?" Additionally, in order to deal with gender bias in language use, spokesman has been replaced by spokesperson; mail carrier has been used instead of mailman. However, there is still disagreement on the use of singular pronoun. For example, invite a friend to come if can. In this case, they are preferred here to avoid gender bias, however, maybe somebody will say they do not like it ${ }^{[9]}$.

\subsection{Social culture}

As is known to all, English is a language, which encompass the language features of Anglo-Saxon, Latin, French, Greek, and Germanic ${ }^{[10]}$. Actually, colonial impositions are the main reason for this various language features. The Romans" invasion and settlement has brought about Latin vocabulary. Germanic dialects came from Anglo-Saxons invader, while French language was introduced into English language after the Battle of Hastings in 1066. Therefore, we can find vocabulary which origins from Latin, such as rose, recipe, and dignity; French words such as ballet, bourgeois, and courage. Besides, due to the "classical" education in Middle Ages, a number of Greek words, such as philosophy, floral, psychology, came into English language use ${ }^{[2]}$.

From above, it can be seen that social changes like wars, colonialism and political events have contributed to the variation and change of English language. However, the most prevalent source of variation may be culture-based ${ }^{[9]}$. This will be explained by three examples as following. The first instance 
is that when expressing the meaning of "you"re driving me crazy," some New Yorkers will say "You"re driving me to Poughkeepsie." In this case, the key to understand the sentence is the word "Poughkeepsie" that refers to a mental hospital locally. Therefore, people from other districts of America are very unlikely to understand it ${ }^{[10]}$.

The instance above indicated that the variations of culture-based vocabulary exist at the local level. Then let us move to the national or international level by looking at two other examples. One is about the word "salad", one American gentleman ordered a salad with roast fish sandwiches in a London pub, then surprised to find out that what the waiter served then is totally different from what he had imagined. In that London pub, "salad" actually refers to "a piece of lettuce, a slice of onion and a slice of tomato." While in his country, the word "salad" obviously means more than that. The final example is about the baseball phrases in American English. It was a political talk between American and Moscow in 1995. The talk turned out to be unsuccessful due to the use of baseball phrases in the speech. The speech involves phrases such as "...hitting singles" " ...hit a series of good solid singles..." "... score a great many runs." These baseball metaphors, to Americans, are very understandable. However, to Moscow audience and other people from different culture backgrounds, that will be a challenge ${ }^{[10]}$.

\section{Reflection}

Through the preparation of this essay, I have gained plenty of new ideas. Firstly, as a teacher, the author thinks he should read the research focusing on language, which can help to develop my language awareness. As a teacher, it is important to have insight towards language learning and language teaching theory. Through reading the academic research and also discussing with my colleges may help to improve my teacher language awareness.

Second, if at all possible, the author will strive to employ more functional syllabus, such as situational, topical, and functional syllabus, while selecting a syllabus. The reason for this is that communication competence is extremely important in both real-life language usage and language acquisition. Furthermore, when it comes to teaching methods, the author favors the Language Awareness Approach (such as TBLT, CLT and so on). Students tend to find and develop language under my supervision in this way. In general, students" emotive engagement in language acquisition is crucial. Actually, It may also enhance students" intrinsic drive in this way.

In terms of teaching materials, the author wants to use more fresh words rather than old-fashioned ones that may not appeal to students. Most students who do not study in literature are unlikely to be encouraged to acquire English terms from Shakespeare's masterwork. However, including all of the new vocabulary in instructional is both impracticable and unnecessary. In addition, we should highlight the context when teaching English. We should emphasize appropriacy in particular. Even though it is far more difficult than teaching correct forms of language, students must be aware of how to use language responsibly in a variety of situations.

Another factor worth mentioning is the cultural aspects of language instruction. The study of social culture should be an integral aspect of language instruction. Language use, for example, is directly tied to the gender issue and cultural appropriacy. Language instructors should also strive to have a global viewpoint. That is to say, language teachers should be aware of and accepting of linguistic diversity. We should avoid any linguistic bias towards any dialect of any language as language instructors. It would be fantastic if our students could gain this level of awareness as well.

However, there are several difficulties that need to be addressed. Will emphasizing the culture of the target language in the classroom, for example, contribute to the phenomena of "cultural imperialism?" It indicates that pupils may be heavily impacted by the target culture, downplaying their own traditional culture as a result. Another difficulty is that language evolved at a breakneck pace. Is it feasible to create a 
pedagogic English system for language teaching?

\section{Funding}

(1) Project: College-Level Modal Course (Online): Public English-Practical Oral English (Project Number: 2021xjtz049).

(2) Project: "San Quan Education" (Education for All, Education in the Whole Process, Holistic Education) Project, "Research on Practical Approaches of Moral Education from the Perspective of College English Teachers-Chinese Culture Integrated into Moral Education" (Project Number: 2021xjsqyb05).

\section{Disclosure statement}

The authors declare that there is no conflict of interest.

\section{References}

[1] Bolitho R, Carter R, Hughes R, et al., 2003, Ten Questions About Language Awareness. ELT Journal, 57(3): 251-259.

[2] Arndt V, Harvey P, Nuttall J, 2000, Alive to Language, Cambridge University Press, Cambridge.

[3] Carter R, 2003, Language Awareness. ELT Journal, 57(1): 64-65.

[4] Hawkins E, 1984, Awareness of Language: An Introduction. Cambridge University Press, Cambridge.

[5] Tomlinson B, 1994, "Pragmatic awareness activities.” Language Awareness. 3(3): 119-129.

[6] Bolitho R, Tomlinson B, 1995, Discover English, New Edition, Heinemann, Oxford.

[7] Van LL, Carter R, Nunan D, 2001, “Language Awareness," The Cambridge Guide to Teaching English to Speakers of Other Languages, Cambridge University Press, Cambridge: 160-165

[8] Crystal D, 1987, The Cambridge Encyclopedia of Language, Cambridge University Press, Cambridge.

[9] Yule G, 1996, The Study of Language, Cambridge University Press, Cambridge.

[10] Andrews L, 2006, Language Exploration and Awareness. Lawrence Erlbaum, Mahwah, NJ. 